\title{
A questão indígena e a ação educativa no MAE/USP'
}

\author{
Camilo de Mello Vasconcellos ${ }^{2}$ \\ Carla Gibertoni Carneiro ${ }^{3}$ \\ Judith Mader Elazari ${ }^{4}$
}

A proposta para este texto é discutir as principais reflexões que são desencadeadas junto ao público que frequienta o Museu de Arqueologia e Etnologia da Universidade de São Paulo MAE/USP por intermédio de ações expositivas e educacionais.

Antes, no entanto, de entrarmos nos aspectos específicos do MAE/USP consideramos pertinente abordar a relação existente entre os museus e a Antropologia como campo de conhecimento, sem a intenção de esgotar este tema.

É nosso objetivo apontar como ocorreu, ao longo da trajetória da Antropologia, os movimentos de aproximação, distanciamento e reaproximação dessa disciplina junto aos museus. Cabe salientar que esses percursos estão profundamente relacionados ao modo como as teorias antropológicas foram se desenvolvendo nesse período.

Este caminho foi marcado por profundas mudanças que ocorreram desde o predomínio dos museus enciclopédicos, no final do século XIX onde prevalecia uma vertente antropológica evolucionista à tendência atual de museus etnográficos, onde as próprias culturas passaram a se representar, utilizando o museu como um instrumento de luta política. ${ }^{5}$

Como referido acima, a relação entre a Antropologia e os museus remonta desde meados do século XIX, quando esta disciplina mantinha

1 Trabalho apresentado na mesa 4: salvaguarda parrimonial e educação em museus.

2 Historiador e Educador. Serviço Técnico de Musealização. Museu de Arqueologia e Etnologia.

3 Historiadora e Educadora. Serviço Técnico de Musealização. Museu de Arqueologia e Etnologia.

4 Historiadora e Educadora. Serviço Técnico de Musealização. Museu de Arqueologia e Etnologia.

5 Abreu, R. 2005:101 uma forte associação com as instituições museológicas; o conhecimento antropológico era construído a partir de materiais coletados essencialmente por não-antropólogos, como viajantes, missionários, comerciantes. Nesse sentido, é possível considerar que a Antropologia nasceu nos museus, uma vez que se desenvolveu à medida que se formaram as grandes coleções etnográficas.

Elas forneciam uma das bases para a produção das teorias antropológicas da época. Ao serem reunidos, identificados, classificados e expostos, aqueles objetos, como os relatos de viagem, serviam para demonstrar ou simplesmente ilustrar as teses dos antropólogos vitorianos sobre a evolução da humanidade e seus diversos estágios. ${ }^{6}$

Neste contexto, desenvolveram-se teorias apoiadas em modelos que classificavam a humanidade conforme o estágio de evolução em que as sociedades se encontravam; esses estágios variavam a partir do grau de complexidade, diretamente relacionado à evolução tecnológica.

Estas teorias antropológicas influenciaram o modo pelo qual as exposições eram concebidas nos museus. Gonçalves continua,

$O$ objetivo destes era narrar a história da humanidade desde suas origens mais remotas, reconstituindo essa longa trajetória até chegar ao que entendiam como o estágio mais avançado do processo evolutivo: as modernas sociedades ocidentais ${ }^{7}$

As coleções etnográficas tinham como curadores os antropólogos influenciados por essas teorias evolucionistas. Esses pesquisadores valorizavam os objetos, que eram interpretados no contexto dos processos de evolução e de difusão da cultura.

6 GONÇALVES, J.R.S. O Templo e o Fórum. A invenção do Patrimônio: continuidade e ruptura na constituição de uma política oficial de preservação no Brasil. IPHAN, Rio de Janeiro, 1995:56.

7 Op. Cit. p. 58 
Os primeiros movimentos de crítica dessas teorias apareceram já em fins do século XIX e início do XX. Um dos importantes nomes dentro da Antropologia na linha de oposição aos modelos evolucionista e difusionista foi Franz Boas que propunha que os objetos deveriam ser estudados a partir dos elementos específicos das sociedades e das culturas onde foram produzidos e utilizados e não mais apoiar as interpretações em modelos que desconsideravam os contextos específicos de produção da cultura material acumulada nos museus. Esta nova forma de entender e classificar os objetos influenciou também a forma de exposição desses acervos.

Ainda segundo Gonçalves,

\begin{abstract}
É preciso observar que a partir dessa crítica desloca-se o foco de descrição e análise dos objetos para o seu uso e consequentemente para as relações sociais em que estão envolvidos os seus usuários. São essas relações que nos revelam a função $e$ o significado dos objetos e dos traços culturais presentes em sociedades e culturas específicas ${ }^{8}$
\end{abstract}

Franz Boas defendia que os museus, em especial os de Antropologia, por ser com os quais mantinha uma relação mais efetiva, deveriam desenvolver suas funções educacionais junto ao público não especializado, principalmente de estudantes e professores e também suas funções de pesquisa, estas já mais voltadas aos especialistas. Ao longo de sua trajetória na esfera museológica, tentou aliar essas duas vertentes, no entanto seu esforço foi tornando-se cada vez mais conflituoso, obrigando-o a optar por um caminho que acabou sendo o da esfera acadêmica.

As primeiras instituições museológicas criadas em nosso país, e aqui cabe citar três delas, o Museu Nacional (RJ), o Museu Paraense Emílio Goeldi (PA) e o Museu Paulista (SP) mantiveram, desde o início, coleções etnográficas e arqueológicas, como parte do universo científico da História Natural, o que perdurou até o início da década de 1930. Este cenário modificou-se,

À medida que os arqueólogos e etnólogos tornavam-se mais acadêmicos e tendiam às recém-estabelecidas universidades, observamos o início do esvaziamento dos museus e o conseqüente desprestígio das

$8 \quad$ Op. cit. p.59. coleções cientificas. Essa guinada para as universidades ocorreu acompanhada por mudanças teóricas, resultando na abertura de novas áreas de estudo, muitas vezes com maior visibilidade e status cientifico. ${ }^{9}$

As teorias antropológicas do período mudaram o foco das preocupações dos objetos para as relações sociais e para os significados dessas relações; nesse sentido o objeto perdeu o status de responder a necessidades práticas, e passou a ser o reflexo de demarcação de identidades e posições sociais, podendo ser visto como parte de um sistema de comunicação.

Outros antropólogos, no entanto, vão mais além e sugerem

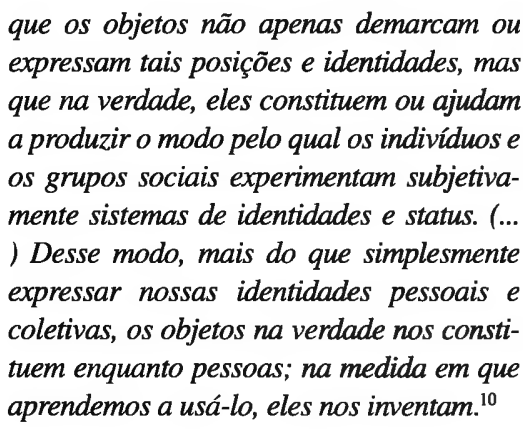

Essa tendência denota uma visão objetificada da cultura, ou seja, como se a cultura existisse independentemente dos indivíduos ou das sociedades.

Alguns antropólogos desse período alertavam sobre a necessidade de que ao estudar uma outra sociedade era necessário ter claros os referenciais de ideologia da sua própria cultura e quais as teorias antropológicas que estavam sustentando a pesquisa.

De certo modo, foi com base numa concepção objetificada da cultura que os pesquisadores ocidentais acumularam vasta quantidade de informações $e$ de objetos materiais que vieram a compor os livros de Antropologia e os museus. ${ }^{11}$

A partir dos anos oitenta podemos verificar um movimento de reaproximação da disciplina antropológica com os museus. Essa tendência reflete uma preocupação mundialmente

\footnotetext{
$9 \quad$ Penha 94

10 Op. cit p. 61.

11 Op. cit p. 62.
} 
crescente que é a de os antropólogos estudarem suas próprias sociedades.

No caso particular do Brasil, esse foi um interesse que existiu desde o surgimento da Antropologia no país, principalmente relacionado aos estudos das sociedades indígenas; já outros países como Estados Unidos, França e Inglaterra tinham seus interesses iniciais voltados para o estudo de "outras culturas"

Além de ter o foco voltado para o estudo da própria sociedade é tendência também, a partir desse período, o estudo sobre a comunidade dos antropólogos e as próprias teorias antropológicas. É nesse contexto que os museus passam a ser alvo de pesquisa entre os antropólogos.

Uma vertente dessa preocupação é pensar se os museus deveriam caminhar num sentido homogeneizador, buscando refletir a existência de uma sociedade com características culturais comuns; ou, ao contrário, no sentido de apontar e dar espaço para as discussões sobre as diferenças sócio-culturais. (Gonçalves, op. Cit., 1995: 64)

Concordamos com Abreu, quando aponta que os museus podem ser vistos como instituições potencialmente decisivas na construção de certas visões sobre diferentes culturas ou construções de alteridades. Ao refletirmos sobre o papel dos museus etnográficos na atualidade, não podemos desconsiderar a influência das teorias antropológicas na formação das coleções, onde a visão do outro pode ser construída a partir de uma visão unívoca, reforçando estereótipos e preconceitos; essa discussão, no entanto, deve estar ao lado de reflexões sobre outras experiências de participações efetivas ou exclusivas focadas na auto-representação ou musealização das próprias culturas, onde há espaço para novas práticas de colecionamento e novos olhares para a cultura material.

Como desfecho para essa discussão, sobre os movimentos de afastamento e reaproximação da Antropologia com os museus, citaremos mais uma vez Gonçalves:

(...) o afastamento que se deu a partir dos anos trinta ocorreu como resultado da crítica devastadora que os antropólogos desenvolveram em relação aos paradigmas evolucionista e difusionista. A rea- proximação a partir dos anos oitenta, por sua vez, foi viabilizada por uma crítica em relação às concepções objetificadas da cultura produzidas pela Antropologia e que ecoavam, de modo etnocêntrico, as ideologias culturais das modernas sociedades existentes no planeta, e que atualiza a lógica das concepções de cultura próprias das nossas sociedades. Isso faz com que pensemos as práticas e os discursos museológicos como empreendimentos sujeitos às intempéries da história e das contradições sócio-culturais. Mais que isso, se essa critica intensifica, por um lado, a nossa consciência da contingência e da precariedade dessas práticas e discursos, por outro, torna bastante aguda a consciência de nossas responsabilidades éticas e políticas ${ }^{12}$

O MAE, embora na sua configuração atual possa ser considerada uma instituição recente traz ao longo da sua trajetória e formação esse histórico de transformações que brevemente apresentamos acima, e mantém acesa as reflexões atuais sobre o papel dos museus antropológicos.

A seguir, discutiremos por intermédio das ações educacionais, como desenvolvemos junto às exposições de longa duração e temporárias e da produção e empréstimo de materiais pedagógicos, a nossa plataforma de atuação junto ao público visitante do MAE/USP. Esta nossa reflexão está baseada nas exposições abaixo relacionadas.

\section{Exposição de Longa Duração:}

- Formas de Humanidade, exposição de longa duração, inaugurada na sede do MAE em1995 e que se encontra aberta até os dias atuais. (concepção museológica de Cristina Bruno e curadoria científica dos docentes do MAE, e especialmente no módulo etnográfico Manisfestações Sócio-Culturais Indígenas, da professora aposentada Sônia Dorta).

12 Op. Cit p.66. 


\section{Exposições Temporárias:}

\author{
Índios do Brasil: fotos históricas dos \\ Museus de Etnologia de Dresden e Lei- \\ pzig, 1991, Estação Ciência (concepção \\ museológica de Cristina Bruno)
}

- Plumária Indígena Brasileira, município de São Carlos, 1993 e 1996(concepção museológica Marilia Xavier Cury e curadoria científica de Sônia Dorta)

Brasil Tupi, 2003 (curadoria científica de Eduardo Góes Neves e Fabíola Andréa Silva)

A partir das avaliações realizadas especialmente junto ao público escolar, uma das principais conclusões a que chegamos foi a de que as exposições etnográficas só têm sentido se estas forem acompanhadas da atuação de educadores que possam facilitar a relação deste mesmo público com a proposta das exposições. Isto se justifica por dois motivos:

1) o público em geral e o escolar especificamente não está acostumado a visitar exposições e a decifrar os seus códigos.

2) A temática indígena refere-se a uma questão bastante importante de ser debatida e aprofundada, mas ao mesmo tempo, é muito pouco conhecida, onde pesam noções extremamente preconceituosas apesar do interesse que desperta nas crianças e nos professores (estes últimos ávidos por novas informações que possam enriquecer o seu trabalho de alguma forma).

Uma de nossas maiores preocupações quanto à clientela escolar, que se constitui em nosso principal público alvo e aquele representado por mais de $90 \%$ de nossos visitantes, diz respeito à forma pela qual devemos receber $\mathrm{e}$ atender a esta demanda cada vez mais numerosa. Temos a convicção da importância desta clientela e, portanto, reforçamos as nossas reflexões e ações para este público, ou seja, não podemos por omissão, nos anularmos como lugar de produção e disseminação de conhecimentos.
Concordamos com Ramos ${ }^{13}$, para quem desenvolver políticas de atendimento aos estudantes não significa transformar o museu em apêndice da escola, nem em simples ilustração do conhecimento ensinado pelo professor em sala de aula. Ao termos clareza sobre nosso papel e nossa atuação, que passa pela pesquisa em relação ao acervo, participação na montagem de exposições fundamentadas e argumentativas, na produção de materiais didáticos de apoio, o museu torna-se mais propício ao ato reflexivo e dialógico, concretizando-se também a partir de diversas atuações e recursos empreendidos

Não se trata de reafirmar a "escolarização dos museus" (LOPES,1991) mas sim de promover a criticidade de papéis educativos que pode ser assumida pelo espaço museológico.

Ao apresentar objetos em contextos expográficos, estamos tratando de processos comunicativos que acabam sendo ou não compreendidos pelo público escolar. Daí a importância da participação do educador não só no processo de concepção de mostras de longa duração, temporárias e itinerantes, mas também no momento de avaliação das respostas que o público escolar apresenta em relação a este processo de comunicação.

Neste sentido, não basta apenas conceber uma exposição ou material didático de apoio ao professor e defini-lo como educativo. É necessário termos claro se atribuímos à prática pedagógica a possibilidade do exercício da reflexão crítica, ou seja, aquela que está intimamente relacionada à possibilidade de haver escolhas $\mathrm{e}$ tomadas de posição por parte do público que nos visita ou que utiliza nossos recursos educativos.

Nesta direção, é fundamental trabalharmos na perspectiva da percepção crítica sobre o mundo em que vivemos a partir da sensibilização em relação ao universo da cultura material, ou seja, dos objetos contextualizados/musealizados em suas mais distintas áreas do saber. Não na perspectiva do conhecimento pronto e acabado, mas na perspectiva do diálogo que propiciará o desvendar de áreas do conhecimento, até então desconhecidas.

Desta forma, o trabalho deve partir dos profissionais dos museus, mas estes devem estar

13 RAMOS, F.R.L. A danação do objeto: o museu no ensino de história. Chapecó: Argos, 2004 
atentos também à formação não só do professor que já atua em sala de aula, mas também do futuro professor que está hoje nos bancos universitários e ainda depende de uma sensibilização para a questão do potencial educativo de nossas instituições. Não basta, portanto, visitar nossas instituições, é necessário trabalhar o como visitar nossos museus. No que eles se constituem, qual o seu papel político, cultural, social?

Por esta razão é que por meio de nossos programas de ação educativa privilegiamos o contato com os professores de Educação Infantil, Ensino Fundamental e Médio antes da visita de seus alunos. Ou seja, é fundamental que trabalhemos com os professores propiciando não só o conhecimento de nossas exposições, mas também a discussão de nossos pressupostos básicos relacionados a uma instituição antropológica tais como o conceito de cultura, etnocentrismo, diversidade cultural, patrimônio cultural territorialidade, dentre outros. É fundamental sensibilizá-los para a particularidade do museu e por conseguinte ganhar a confiança e a participação dos seus alunos quando da visita destes.

Quanto ao futuro professor que ainda está freqüentando a Universidade também oferecemos a oportunidade deste conhecer nosso potencial por meio da possibilidade da realização de estágios em nossa área. Os resultados alcançados por estes alunos em seu crescimento profissional e pessoal vêm nos demonstrando que este esforço é fundamental no que diz respeito ao amadurecimento acadêmico e às perspectivas que se abrem para a atuação destes futuros agentes multiplicadores em sala de aula.

Nesta direção é que entendemos a figura do educador de museus como o mediador da relação entre o público e as exposições, ou dos materiais pedagógicos especialmente concebidos para este mesmo público. $\mathrm{O}$ educador deve ser antes de tudo um provocador: do conhecimento, da situação e da problemática a ser enfrentada. Não devemos deixar de afirmar que quando nos deparamos com o público escolar tudo deve ser adaptado às diferentes faixas etárias, ao interesse das mesmas e na prática curricular que estabelece "pontes" com o conceito museológico que fundamenta a exposição ou recurso pedagógico a ser explorado. Neste con- texto a informação bem trabalhada pode assumir o sentido de provocação.

Finalmente, não podemos também nos esquecer de enfrentar mais outro grande desafio: aquele de conquistar novos públicos. Não devemos nos deixar acomodar pela afluência apenas do público escolar que acaba justificando os nossos esforços na concepção de materiais e no atendimento cotidiano. É necessário irmos ao encontro daqueles que, fora da escola, nos vêem ainda como algo totalmente estranho: aí se encontram os cidadãos da terceira idade, os moradores carentes do nosso entorno, os deficientes visuais, auditivos e mentais, categorias de trabalhadores, enfim, aqueles para os quais não foi dada nenhuma oportunidade, mas que expressam uma vontade imensa em descortinar um universo ainda inexplorado.

\section{Programa de Recursos Pedagógicos:}

Paralelamente a ação educativa desenvolvida nas exposições de longa duração, temporárias e itinerantes, a equipe de educadores do MAE/USP desenvolve materiais pedagógicos relacionados às temáticas de pesquisa desenvolvidas pela Instituição. Destacaremos aqui os recursos diretamente relacionados à temática indígena:

\section{Kit de objetos infantis indígenas}

Este material didático é um recurso que propicia o conhecimento sobre alguns aspectos da cultura infantil em diferentes sociedades indígenas.

Propomos, por intermédio deste kit, desafios que envolvem várias habilidades cognitivas: manuseio, observação, questionamento, investigação, comparação e reflexão, além de desenvolver atitudes que permitem a cada um perceber a diversidade cultural dos povos indí- 
genas a partir da análise e do conhecimento de algumas de suas principais características: a socialização das crianças.

A utilização deste material didático com o público escolar pretende alcançar alguns objetivos, tais como:

1. Discutir a relação entre diferentes artefatos, documentos, suportes e veículos de informação que possibilitem a compreensão da infância em diferentes grupos indígenas;

2. Subsidiar professores para que preparem seus alunos para uma visita ao MAE / USP, que possui em seu acervo importantes coleções etnográficas brasileiras;

3. Propiciar situações de ensino que envolvam a questão indígena, especialmente relacionada à diversidade cultural entre estas sociedades;

4. Demonstrar que os museus podem ser vistos como "Laboratórios Pedagógicos" sugerindo e oferecendo formas alternativas e específicas de ensino e aprendizagem;

5. Traçar paralelos entre as experiências lúdicas das crianças indígenas e não indígenas;

6. Compreender diferentes formas de socialização de crianças em diferentes sociedades;

7. Contribuir para o aprofundamento da reflexão sobre diversidade cultural entre as sociedades indígenas, aprendendo a ver a diferença como uma riqueza no desenvolvimento do respeito entre as diferentes culturas.

Os professores interessados em utilizar este kit, com seus alunos em sala de aula, passam por uma orientação prévia, um "treinamento"; neste momento procuramos explorar o potencial educacional do material.

Compõem o kit:

1. Objetos infantis indígenas: apito e pião Kayabi, boneca Karajá, arco e flecha Nambikwara, ralador Enawene-Nawe e cesto cargueiro Panará;

2. Texto cientifico: Os brinquedos e a socialização da criança indígena, da etnóloga do MAE/USP, professora Nobue Myazaki, com a contextualização dos objetos acima citados;

3. Painéis fotográficos com os seguintes temas: Brincadeiras, Contato, Modelagem da boneca Karajá e Crianças;

4. Pranchas com mapas e ilustrações sobre aspectos do cotidiano de diferentes grupos indígenas;
5. Vídeo Peju Katy Kyrimgue'i - "Venham todas as crianças" um recorte no cotidiano de crianças da aldeia Guarani Krukutu (Parelheiros - São Paulo/SP).;

6. Sugestões de atividades pedagógicas;

7 Sugestões bibliográficas.

A partir desta vivência é possível conhecermos as deficiências de formação destes professores, os preconceitos, os estereótipos e os saberes que eles trazem consigo.

Procuramos mostrar também que a ação educativa desenvolvida a partir deste material suscita uma série de temas para discussão em sala de aula, tais como:

O papel dos brinquedos e brincadeiras no processo de socialização das crianças indígenas e dos alunos não indígenas,

A diversidade cultural dos indígenas;

-A pesquisa etnográfica e o conhecimento sobre as sociedades indígenas;

A divisão sexual de trabalho nas diferentes sociedades indígenas;

As escolas indígenas e não-indígenas: paralelos entre elas;

-A aprendizagem, por parte das crianças, das tarefas relacionada ao cotidiano em algumas sociedades indígenas e a exploração do trabalho infantil nas sociedades não indígenas.

O Caderno de Atividades que acompanha o kit contém sugestões de utilização para cada um de seus componentes e elas podem ser adaptadas às diferentes faixas etárias, desde a educação infantil até o ensino médio.

O kit tem sido também trabalhado com outros públicos e em outros locais que não a nossa sede, como, por exemplo, na Escola de Aplicação da Faculdade de Educação da USP e nos Centros de Educação Unificados CEUs.

Desenvolvemos oficinas pedagógicas para professores em CEUs durante eventos organizados sobre a questão indígena. É possível observar a falta de materiais educativos com viés científico sobre esta temática e a boa recepção do kit, neste sentido, como uma forma de suprir esta demanda.

Uma oficina também foi oferecida aos professores indígenas das escolas indígenas das aldeias Guarani, no bairro de Parelheiros na cidade de São Paulo, denominadas CECIs. Além do reconhecimento de objetos tradicionais e da descoberta 
de artefatos feitos por outras sociedades indígenas, o contato com o kit despertou o interesse em elaborar um recurso semelhante para a atuação junto aos alunos em suas escolas; As Escolas Diferenciadas Indígenas tem como objetivo incentivar a produção de material pedagógico específico.

Finalmente, o kit tem sido utilizado em Atividades de Férias que oferecemos para o público infanto-juvenil. Como estas atividades possuem objetivos mais lúdicos, as brincadeiras fluem com mais facilidade.

\section{Guia Temático para Professores: Volume Manifestações Sócio- Culturais Indigenas}

A série Guia Temático para Professores foi concebida como um instrumento que visa facilitar a relação dos professores com a exposição de longa duração Formas de Humanidade possibilitando um melhor aproveitamento de seu potencial pedagógico, e delinear ações multiplicadoras que contribuam para a comunicação das coleções e pesquisas promovendo a aproximação de uma instituição museológica com distintos segmentos da sociedade.

Este recurso pedagógico pressupõe desafios que envolvem o olhar, o observar, o sentir, o questionar, o investigar e o comparar conceitos e informações referentes às várias temáticas abordadas na Exposição. Por meio dele procurase favorecer o desenvolvimento de habilidades cognitivas/expressivas dos alunos, a partir da mediação dos professores, contribuindo assim para o processo de aprendizagem.

Destacaremos aqui o volume referente ao módulo Manifestações Sócio-Culturais Indígenas, por abordar especificamente a questão indígena.

Os Guias Temáticos estão divididos em três partes que dialogam entre si:

$1^{\mathrm{a}}$ parte: Texto científico referente às temáticas do módulo em questão.

$2^{\mathrm{a}}$ parte: encartes com:

-apresentação do MAE/USP

-apresentação do Guia

-sugestões de atividades educativas para serem desenvolvidas antes, durante e depois da visita ao MAE/USP; -ficha de avaliação do Guia e de seu uso para ser enviada pelos professores ao MAE/ USP.

$3^{\mathrm{a}}$ parte: Fotos de objetos da exposição, em pranchas que podem ser manuseadas pelos usuários.

O texto científico foi escrito pela etnóloga e curadora desse Setor, Profa Dra Sonia Dorta, hoje aposentada, em linguagem acessível. Houve uma grande preocupação em esclarecer questões relacionadas ao conceito do que é "ser índio" no Brasil, à diversidade cultural dos indígenas brasileiros e também dar elementos para se desconstruir os estereótipos sobre a questão indígena. Os termos muito específicos ou polêmicos foram colocados em "boxes" separados para que ficassem mais claros. O texto é bastante ilustrado, principalmente com fotos de objetos do próprio acervo do museu.

As atividades pedagógicas, propostas pelos educadores do MAE, procuram desafiar, sugerir e instigar a aprendizagem sobre a questão indígena, dando condições tanto para que o professor possa preparar-se para uma visita ao Museu, bem como para orientar seus alunos.

As pranchas com fotos de objetos são apresentações bidimensionais dos mesmos, cuja análise leva à reflexão sobre os diferentes tipos de investigação sobre a cultura material e nos permite conhecer "novas dimensões da leitura e interpretação" de objetos.

Estes dois tipos de encartes, as propostas pedagógicas e as pranchas com fotos, possibilitam um dinamismo maior nas visitas a exposição Formas de Humanidade assim como promovem uma interdisciplinaridade tanto com relação às matérias dos currículos escolares como entre ciências humanas, principalmente arqueologia, etnologia e história.

É importante salientar, ainda, que este recurso pedagógico foi pensado especialmente para professores utilizarem com seus alunos na escola e também no espaço expositivo.

\section{Kit de Objetos Arqueológicos e Etnográficos}

Este kit foi elaborado para que os professores possam trabalhar habilidades intelec- 
tuais semelhantes aos dos materiais didáticos já descritos, assim como para dar oportunidade aos professores prepararem seus alunos com uma série de conhecimentos que ao chegarem às exposições do MAE, possam aprofundar seus questionamentos e conhecimentos.

Este kit por razões históricas de sua elaboração, privilegia o trabalho do arqueólogo e o estudo de arqueologia. Entretanto, possui dois objetos etnográficos a partir dos quais podemos possibilitar a reflexão sobre o trabalho do etnólogo. Além disso, direciona uma discussão sobre as diferenças e semelhanças entre estas duas disciplinas a arqueologia e a etnologia.

A partir das reflexões apresentadas acima, que refletem nossa atuação como mediadores no contexto de um museu antropológico, acreditamos estar contribuindo para a sensibilização do público a respeito da importância da questão indígena em nosso país e que encontra no MAE um canal de referência para tanto.

\section{Bibliografia}

Abreu, R. Museus Etnográficos e práticas de colecionamento. Revista do Patrimônio Histórico e Artístico Nacional $n^{\circ}$ 31. IPHAN, Brasília, 2005.

Carneiro, C.G, Elazari, J. M. e Vasconcellos, C.M. Recursos Pedagógicos: kit de objetos infantis indígenas. Revista do Museu de Arqueologia e Etnologia da USP. n 14. São Paulo, 2004.

Elazari, J. M. Recursos pedagógicos de museus: kit de objetos arqueológicos e etnográficos. Revista do Museu de Arqueologia e Etnologia da USP. nº 10. São Paulo, 2000.

Gonçalves, J.R.S. O Templo e o Fórum. A invenção do Patrimônio: continuidade e ruptura na constituição de uma política oficial de preservação no Brasil. IPHAN, Rio de Janeiro, 1995. p. 55-66
Lopes, M.M. As Ciências Naturais e os museus no Brasil no século XIX. Tese (Doutorado) - Faculdade de Filosofia Letras e Ciências Humanas, Universidade de São Paulo, São Paulo, 1993.

Meneses, U.B. Identidade Cultural e Museus. Anais do III Fórum Estadual de Museus. Santa Maria/RS, p. 17-26, 1992.

Penha, D.H. O papel dos museus antropológicos no Brasil. Caderno de Ensaios. Rio de Janeiro: IPHAN. $\mathrm{n}^{\circ} 02$, p. 29-40, 1994.

Köptcke, Luciana Sepúlveda. Analisando a dinâmica da relação museu-educação formal. In: $O$ formal $e O$ não-formal na dimensão educativa do museu. Caderno do Museu da vida. MAST, Museu da Vida, 20012002.

Lopes, Maria Margaret. Museu: uma perspectiva de educação em geologia., Faculdade de Educação da UNICAMP, 1988. (Dissertação de mestrado)

A favor da desescolarização

dos museus. In: Educação e Sociedade, Vol. 3, n 40, Campinas, 1991.

Resta algum papel para o educador ou para o público nos museus? In: Boletim do CECA - Brasil. Ano I, n 0, março de 1997.

Marandino, Martha. Construindo princípios para educação em museus de ciências. In: II Seminário Internacional de Educação em Campinas. Texto Mimeografado, 2004.

O mediador na educação nãoformal: algumas reflexões. In: $O$ formal e o não-formal na dimensão educativa do museu. Caderno do Museu da vida. MAST, Museu da Vida, 2001-2002.

Ramos, Francisco Régis Lopes. A danação do objeto: o museu no ensino de História. Chapecó: Argos, 2004.

Rizzi, Maria Cristina de Souza Lima \& Vasconcellos, Camilo de Mello. A Ação Educativa na Exposição Brasil 50 Mil Anos: princípios e propostas. In: Brasil 50 Mil Anos - uma viagem ao passado pré-colonial. São Paulo: MAE/EDUSP, 2001.

Vasconcellos, Camilo de Mello. A função educativa de um museu universitário e antropológico: o caso do Museu de Arqueologia e Etnologia da USP. In: $\mathrm{Ca}$ dernos do CEOM, Campus de Chapecó-SC, $n^{\circ} 21$, 2005. (Museus, pesquisa, acervo e comunicação) 